\title{
Euthanasia: Ethical or Non-Ethical
}

\author{
Aakansha Saraf ${ }^{1}$, Ishaan Gupta ${ }^{1}$, Pooja Chaudhuri' ${ }^{2}$, Nitesh Malhotra ${ }^{3}$, Aksh Chahal ${ }^{4}$ \\ ${ }^{1}$ BPT Student, MM Institute of Physiotherapy and Rehabilitation, Maharishi Markandeshwar (Deemed to be \\ University) Ambala. Haryana, India, ${ }^{2}$ Associate Professor, Department of Physiotherapy University of Science \\ and Technology, Meghalaya, India, ${ }^{3}$ Assistant Professor, Amity Institute of Physiotherapy, Amity University, \\ Uttar Pradesh, India, ${ }^{4}$ Professor, MM Institute of Physiotherapy and Rehabilitation, Maharishi Markandeshwar
}

(Deemed to be University), Ambala, Haryana, India

\begin{abstract}
'Euthanasia' is a compound of two Greek words 'eu' and 'Thanatos' meaning, a good death. It is a practice of intentionally ending life to relieve from suffering and pain which are immeasurable within human limits. Basically it's ending of life for the impaired, which is unable to achieve 'moksha' even after persistently or willingly trying to. In medical language, 'termination of life by doctors at request by the patient's close relatives or attendants for patient bedridden for years struggling and unable to revive. Euthanasia is a complex matter of concern. It poses both, positive and negative implications which should be worked on and implemented under guidelines by administrations at different settings. As certain developed nations have legalized Euthanasia, their proposals and recommendations for considerations can be considered as a base for projecting Euthanasia in developing countries like India.
\end{abstract}

Keywords: Euthanasia, legalized, implication, India.

\section{Introduction}

"Death is Not the Greatest Loss; The Greatest Loss is Dying within While One Lives”.

'Euthanasia' is a compound of two Greek words 'eu' and 'Thanatos' meaning, 'a good death. Itis a practice of intentionally ending life to relieve from suffering and pain which are immeasurable within human limits. Basically it's ending of life for the impaired,which is unable to achieve 'moksha' even after persistently or willingly trying to. In medical language, 'termination of life by doctors at request by the patient's close relatives or attendants for patient bedridden for years struggling and unable to revive. Everyone who wishes well for the

\footnotetext{
Corresponding Author:

Aksh Chahal

Professor, MM Institute of Physiotherapy and

Rehabilitation, Maharishi Markandeshwar (Deemed to

be University), Ambala, Haryana, India

e-mail:drakshchahal@gmail.com
}

concerned want him/her to be free from the vicious cycle of sufferings and merciless they face on daily basis. Like the other terms filched from history, euthanasia had different meanings depending on usage. The first apparent credit goes to historian Suetonius, who described how Emperor Augustus, dying quickly and without suffering in the arms of his wife, Livia, experienced euthanasia he wished for. Francis Baconin the $17^{\text {th }}$ century used euthanasia in medical context to refer it as an easy, painless, and happy death ${ }^{(1)}$. He referred to an 'outward euthanasia', the term 'outward' he used to distinguish from a spiritual concept the euthanasia which regards the preparation of the soul. The author would like to highlight case of Aruna R. Shaunbagh ${ }^{(2)}$ case which brought the entire nations vision towards passive euthanasia. Yes! It is the case which brought about the point of Euthanasia in India. This case attained limelight after the remorseless death of a nurse named, Aruna. Aruna was an Indian nurse who spent 42 extensive years in a vegetative state as a result of the sexual assault in 1973. While working as a junior nurse at King Edward Memorial Hospital, Parel, Mumbai, and Shaunbag was sexually assaulted by a ward boy. The boy strangulated 
her with a dog chain around her neck which cut off oxygen supply to her brain leaving her deaf,blind, and deaf, paralyzed. From the day of her assault till the day she died on May 18, 2015 she survived on mashed food, she couldn't move her hands or legs couldn't talk or perform basic function expected from a human being. To a surprise, the accused was charged with attempted murder, and was sentenced for seven years imprisonment which was reduced to six years and was finally set free in 1980. While, Aruna remained in a vegetative state for rest of her life it was 2009, a petition was accepted by the honorable Supreme Court on insistence of a journalist and activist, Pinki Vikrani. A 1994, constitutional validity of Indian Penal Code Section (IPC Sec) 309 was challenged in the Supreme Court ${ }^{(3)}$. The Supreme Court declared that IPC Sec 309 is unconstitutional, under Article 21 (Right to life) of the constitution in a landmark judgment. But later, Vikrani questioned the court that if in the Article 21 of the Constitution of India can give Right to Life then why not Right to Death ${ }^{(3)}$. The Supreme Court of India later felt that Aruna wasn't brain dead and could respond to certain stimulus. So, the petition was rejected. But,this case brought a revolution in the history of medical profession within India. Later, the panel of judges finally accepted the petition and granted legalized passive euthanasia making it a sensible judiciary act. Passive euthanasia is grossly different from active euthanasia, as the latter induces death or end the life of patient by administration of lethal agents. The apex court hereby, laid stringent guidelines under which passive euthanasia would be legally allowed only via a high-court monitored mechanism. An author has a question, was Aruna living a life or strangulated everyday for 42 years on the hospital couch? Did she deserve to be on the couch for 42 long years?

Another victim of circumstances, who laid on the death-bed hoping to donate all organs of his body for a noble cause, Kolavennu Venkatesh, a young chess player from Hyderabad who fought a bitter legal battle to end his life before a debilitating muscular degeneration killed him, ended his struggle quietly in 2004. The 25 years old man, struggling for past 18 years pleaded for euthanasia. Antipathy is not a word but it is the position or it is a feeling because of which Jurisprudence has been generated ${ }^{(3)}$.For years a debate is going on to legalize Euthanasia in India, may it be a case of Venketesh or Aruna. It is one of the much debated subjects throughout the world. The debate has been increasingly significant because of the recent development in Netherlands and
England wherein euthanasia is allowed. As a result, many nations across are now hotly debating whether to follow or not the Dutch example ${ }^{(4)}$. In India,many health professionals, philosophers, psychologists have expressed their views for the same. Some are in favor while others are against. According to the author, Euthanasia is a way by which a doctor can free a patient from trap of misery. An individual who once wanted to live,be happy is now on the verge of daily suffering, whose dreams have been crushed and along with them their family is struggling,who want to wish to bring him out of it and wish for an end for him with a heavy heart. Once a cheerful person lying on the hospital bed for all eternity, whose goals have now become a grave, whose identity is just a 'ward patient 'helpless'. Think of him/ her "who once wanted to fill life with colors, wanted to nurture himself, grow and achieve something great in life,is lying pale and lifeless. Think for the mother who gave birth to a child, wishing success and fortune, blessed him to achieve something great in future, but seeing him lifeless, struggling, pale may give agony to her Darwin's theory of 'Survival of the fittest 'says that all species of organisms arise and develop through natural selection, inherited variations that increases the individual's ability to compete, survive and reproduce. In simple language the specie that is fit to reproduce and compete in life is only fit to live in this world. But if an individual is incompatible toper form these acts and dependent for years to come isn't it unfair to keep them in agony forever. To the honest, the author thinks, if Euthanasia is wrong the same should be applicable for Medical Termination of Pregnancy (MTP) ${ }^{(3)}$. One may be thinking why? So, it would be wise to say that the person lying in a vegetative state couldn't melt one's heart enough to end his sufferings then what about ending a life that is not yet born. A distinction may be made between Euthanasia and abortion. Death intervenes before life in earnest has even begun. In Euthanasia people make decision about death at the other end of life, after in earnest has ${ }^{(2)}$. But the Constitution doesn't give right to end a suffering. How unfair is that? If mercy killing is unethical then MTP should also be considered the same. If the Supreme Court can approve MTP, then why not euthanasia?

The authors of the article analyzed both aspects against and favor of the concerned topic. As we recognize that it's not only for competent patients, but also incompetent ones who can suffer from conditions that make their lives not worth living ${ }^{(5)}$. We cannot 
effect legal change in one go; we shall appreciate for liberalization of law. Once even if any modest change is made, people might realize that the next step and consecutive are also acceptable, even if we cannot see it now ${ }^{(4)}$ The argument invoked by legal Right to die opponents is that the Right will be abused and that no legal safeguards can prevent its abuse. Example for voluntary euthanasia always a written consent is a legal requirement but this is not always obtained ${ }^{(6)}$. In long run, the euthanasia may definitely be misused to end up the lives of the care needy or people suffering from terminal illness, or people who are to undergo transplantations ${ }^{(7)}$. In earlier times, majority of people died before they reached the hospital but now due to gradual medical advancement life can be prolonged but not to the extent of bringing back the dead ones. Malafide Intention ${ }^{(7)}$, in the era of declining mortality and justice, there is a possibility of misusing euthanasia for inheriting the property of the patient. 'Mercy killing' should not lead to 'killing mercy' in the hands of the noble medical profession ${ }^{(7)}$. Previously disease outcomes was discussed in CURE but in contemporary world of disease and debated in terms of $\mathrm{CARE}^{(7)}$. CONCLUSION:Euthanasia is a complex matter of concern. It poses both, positive and negative implications which should be worked on and implemented under guidelinesby administrations at different settings. As certain developed nations have legalized Euthanasia, their proposalsand recommendations for considerations can be considered as a base for projecting Euthanasia in developing countries like India.

\section{Conflict of Interest: Nil}

\section{Source of Funding: Self}

Ethical Clearance: Nil

\section{References}

1. Sinha VK, Basu S. and Sarkhel S. Euthanasia: An Indian perspective: Indian J Psychiatry. 2012; 54(2):177-183.

2. Aruna Ramchandra Shanbaug vs. Union of India \& Ors. Writ Petition (Criminal) no. 115 of 2009, Decided on 7 March, 2011.

3. Goel V: Euthanasia-A dignified end of life! International NGO Journal. 2008; 3 (12): 224-231.

4. Math SB and Chaturvedi S.K Euthanasia: Right to life vs. right to die: Indian J Med Res. 2012; 136(6):899-902.

5. Kalal N. Euthanasia: Right to Live and Right to Die: International Journal of Current Research. 2018; 10 (11): 75543-75546.

6. Benatar D; A legal right to die: responding to slippery slope and abuse arguments. Curr Oncol. 2011; 18(5):206-207.

7. Roy C: Position of Euthanasia In India-An Analytical Study, 2011. 